\title{
Bone infections. About 24 cases of lower limb fractures
}

\author{
Souna B. Seyni ${ }^{1}$, Ibrahima Farikou ${ }^{2}$, Moumouni H. ${ }^{3}$, Harouna Yacouba G. ${ }^{4}$ \\ ${ }^{1,3,4}$ Department of Orthopedics and Trauma, Lamordé National Hospital, Niamey, Niger \\ ${ }^{2}$ Orthopedic Service, National centre for the Rehabilitation of the disabled of Yaoundé, Cameroon.
}

\begin{abstract}
Background: Bone infections are common in orthopedic surgery. The treatment is medical and surgical.

Materials and methods: we carried a retrospective study during to 12 months involving 24 medical records of long bone fractures of the lower limb. The aim of the study was to determine epidemiological, clinical and therapeutic aspects of bone infections of long bone fractures.

Results: In 16 cases of the 24 bone infection had occurred in an open fracture. The tibial segment was the most affected with 14 cases (73\%) of skin opening lesions type 2 Cauchoix. In 8 cases, there were infections developed from close fractures. The interval of admission extended 4 days to 7 months. Healing had occurred between 6 to 18 months of treatment with persistence of a fistula in 2 cases.

Discussion: Bone infections remain a public health problem whatever the country, because of the morbidity and the particularity of their therapeutic management according to each patient. Aaccurate classification of these bone infections may facilitate their management.
\end{abstract}

Conclusion: Continuous improvement of hospital stay and operating theater, a well-targeted anti biotherapy will contribute to reduce the frequencyof bone infections.

Keywords: long bone; lower limb; fractures; infections.

\section{$L$ ' infection osseuse}

à propos de 24 cas de fractures du Membre Inférieur

Résumé

Introduction : Les infections osseuses sont fréquentes en chirurgie orthopédique. Le traitement est médicochirurgical.

Méthodologie : nous avons mené une étude rétrospective sur 12 mois et portant sur 24 dossiers d'infections osseuses sur os long fracturé du membre inférieur. Le but était de définir les aspects épidémiologiques cliniques et thérapeutiques de ces infections osseuses sur os long fracturé

Résultat: Dans 16 cas l'infection osseuse était survenu sur une fracture ouverte. Le segment jambier était le plus retrouvé avec 14 (73\%) cas d'ouverture cutanée de type 2 de Cauchoix . Dans 8 cas, il s'agissait de cas d'infection osseuse développée sur des fractures fermées. Le délai d'admission était de 3jours à $7 \mathrm{mois}$.La guérison était intervenue entre 6 à 18 mois de traitement avec persistance d'une fistule dans 2 cas.

Discussion : les infections osseuses constituent une préoccupation quelque soit le pays, à cause de leur morbidité et de la particularité de la prise chez chaque patient. Une bonne classification de ces infections facilitera leur prise en charge.

Conclusion : l'amélioration continue des conditions d'hospitalisation et du bloc opératoire, une antibiothérapie bien ciblée contribueront à réduire la fréquence des ses infections osseuses.

Mots clés : Os long-Membre- Fracture-Infections

\section{Introduction}

Bone infections are common in orthopedic surgery especially in the presence of an implant. In many cases they become chronic. The treatment is medical and surgical. All surgery involves some degree of risk of occurrence of infection of operatory site. This risk increases when an implant is put in place. Various preventive measures are undertook to reduce the risk of infection, including patient preparation, sanitation of the environment of the operating room and the prescription of prophylactic antibiotics. All these measures help to reduce the risk of postoperative site approximately $2 \%$ in use of implant in orthopedic surgery [1]. In our context the overall management of bone infection has a considerable social cost. Antibiotics are not normally accessible to poor patients; the long duration of hospitalization (required for treatment) contributes to switch these patients in poverty.

We carried out within the Department of Orthopedics and Trauma Surgery of Lamordé Hospital a retrospective study of 24 cases collected over 12 months period.

The aim was to determine the clinical epidemiological and therapeutic aspects of these bone fractured infections. 


\section{Patients and methods}

This was a retrospective study extended over 12 month's period (1st April 2011 to 31 March 2012). Were included in the study all patientsWhatever the age and the sex treated for fracture of a pelvic limb complicated by bone infection during the study period. Only locations with long bones (femur, tibia, and fibula) were included in this study. Septic osteo arthritis and bone infections in non fractured bones were not selected for the study.

The medico - surgical treatment was based on the antibiotherapy(Mesporin / oxacillinoxacillin / lincocine ) associated with surgical excision of the infected soft tissue and sequestrectomy if necessary. The ablation of the osteosynthesis material was performed and when needed replaced by an external fixator or a plaster cast.The filling of bone defects or loss of soft tissue was also carried out upon request.

We have classified cases bone infection in type I, type II andtype III.

During the treatment of bone infection, the surveillance was focused not only on the evolution of clinical and adiological signs but also on the results of biological samples such as blood count, erythrocyte sedimentation rate.

\section{Results}

A total 24 cases of long bones infections have been observed during the study period.The delay of admission was 3 days at 7 month.

In 16 cases of bone infection had occurred on an open fracture (Figures 1.3, 4.6). The tibial segment was most involved with 14 (73\%) cases of cutaneous opening type 2 Cauchoix classification.

In 8 cases, there were cases of bone infection developed in closed fractures (direct contamination of the bone intraoperatively,inoculation, tissue manipulation,implants).

Clinical signs were dominated by hyperthermia. From 24 infected patients, a pathogen was isolated 10 times. Staphylococcus aureus was the most germs met 9 times and Pseudomonas was isolated 1 time.

During the treatment of the infection, the decision to retain or remove the osteosynthesis material was taken as follows:

-The material was retained if, despite of infection, the mountage is stable and the existence of an evolutionary callus confirmed by plain X-ray control (17 cases).

-In case of partial removal of osteosynthesis material or its holding very poor and no signs of consolidation on $\mathrm{X}$-ray, the material was completely removed and replaced with an external fixator (7 cases).

Two cases of inter tibio- fibular graft was necessary to fill significant loss of bone substances.

We performed 4 cases of recovery of loss substance soft parts using a full thickness skin graft after granulation of the wound (photo 5).

Healing had occurred between 6-18 months of treatment with persistence of a fistula in 2 cases (Fig. 2).

\section{Discussion}

The management of bone infection raises two complex issues: the treatment of infection and bone healing. One treatment applicable to all cases of bone infections does not exist. According to Parsons [2], each patient with a bone infection should receive an appropriate care to his condition, thus avoiding the significant morbidity entailed the spread and aggravation of infection. The treatment of bone infection requires isolation of the pathogen, debridement of necrotic tissue, excision, reconstruction of bone and soft tissue, and stabilization of the bone [2]. The isolation of the pathogen with culture and sensitivity to antibiotics is a weakness of our study; this is related to the technical difficulties encountered by the laboratory of our institution and with the self-medication of patients contributing to the beheading of infection. In the management of bone infections with osteosynthesis material in situ, the issue of retention or removal equipment is acute. Faced with this problem we proposed therapeutic approach according to known 3 types classification learn from previous reports $[3,4,5,6,7,8]$.

In case of type I infection with the presence of a stable osteosynthesis material, with radiological signs of advanced consolidation, the material should be retained and control infection must be done by surgical means and ablate material from the consolidation be effective .

Infection with a type II material stable osteosynthesis with radiographic callus formation which is not progressing, the therapeutic approach will be the same as in the Type I. Except that means helping to stimulate bone healing should be involved in support namely ultrasound, electromagnetic field, limited surgical procedures, boosting.

In case of type III one infection, with no callus on radiographs, the removal of material and replacement by other means for better bone stabilization must be indicated.

In our study, we encountered essentially similar situations to type I and type III. Therefore, in the majority of cases, in type I (17cases), we proceeded to medical and surgical management with conservation of the material 
which was removed once the consolidation were effective relayed by additional immobilization by plaster for some weeks.

For the type III, we opted for the removal of material. In case of loss of substance less than $2 \mathrm{~cm}$, we used Ilizarov or Hoffmann external fixators ( 5 cases including once for the femur and 4 times for the tibia) in compression in order to support the bone healing (figures 2, 6, 7 and 8). We performed 2 inter tibio-fibular grafts for significant circular loss of substances in case of intact fibular in our series.

According toJamsen et al [9], Renaud et al [10], and Namba et al [ 11] the risk factors such as obesity, diabetes, prolonged exposure of the operative field contribute to the increased risk of surgical site infection. The retrospective nature of our study has not allowed us to measure the body mass index in our patients nor to accurately determine the time spent on each surgery.

\section{Conclusion}

The bone infection is common and is a concern in orthopedic surgery, because of the dual therapeutic challenge it poses, and its high morbidity. The therapeutic management is medical and surgical and requires a multi disciplinary cooperation including orthopedic surgeon, plastic surgeon, and infectious disease specialist. Improved surgical procedures and inpatient care will reduce its frequency without making it disappear completely.

\section{Références}

[1]. Kigera J W M. Incidence of early post operative surgical infection after primary total hip arthroplasty in the African setting. EAOJ; Vol.7: March 2013.p 8-9.

[2]. Parsons B, Strauss E. Surgical management of chronic osteomyelitis . A J Surg Osteomyelitis.2004. 188 .57S-66S

[3]. Carlo Luca R , Delia R, Nicola L, Lorenzo D. Bone and joint infections in adults: a comprehensive classification proposal EurOrthopTraumatol. 2011 May; 1(6): 207-217.

[4]. Romanò CL, Zavatarelli GA, Tinti M (2006) Meani E Profilassidell'infezionenell'osteosintesi e classificazione "ICS” come guida al trattamento. ArchOrtopReumatol 117(3):8-11

[5]. Court-Brown CM, Keating JF, McQueen MM (1992) Infection after intramedullary nailing of the tibia. Incidence and protocol for management. J Bone Joint Surg Br 74(5):770-774.

[6]. Green SA, Larson MJ, Moore TJ (1987) Chronic sepsis following intramedullary nailing of femoral fractures. J Trauma 27(1):5257.

[7]. Laky R (1989) Results of treatment of infected osteosynthesis cases. MagyTraumatolOrthop 32(3):187-193

[8]. Romanò C, Logoluso N (2009) Low intensity pulsed ultrasound for the treatment of bone delayed union or nonunion: a review. Ultrasound Med Biol 35(4):529-536.

[9]. Jamsen, E., Nevalainen, P., Eskelinen, A., Huotari, K., Kalliovalkama, J. and Moilanen, T. Obesity, diabetes, and preoperative hyperglycemia as predictors of periprosthetic joint infection: a single-center analysis of 7181 primary hip and knee replacements for osteoarthritis. J. Bone Joint Surg. Am. 2012; 94(14):e1011-1019.

[10]. Renaud, A., Lavigne, M. and Vendittoli, P.A. Periprosthetic joint infections at a teaching hospital in 1990-2007. Can. J. Surg. 2012 ;55(6):394-400.

[11]. Namba, R.S., Inacio, M.C. and Paxton, E.W. Risk factors associated with surgical site infection in 30,491 primary total hip replacements. J. Bone Joint Surg. Br. 2012 ;94(10):1330-1338.

\section{Annexes}

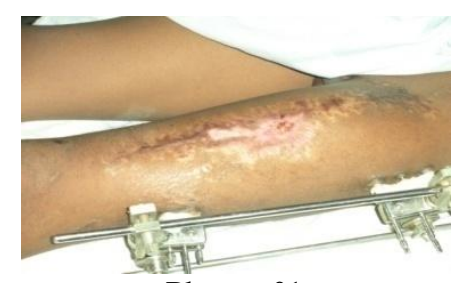

Photo ${ }^{\circ} 1$

Photo $\mathbf{n}^{\circ} \mathbf{1}$ :Open femur fracture infected, stabilisation by hoffmann external fixator, healing with fistula .

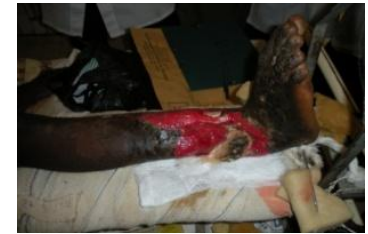

Photo $n^{\circ} 2$

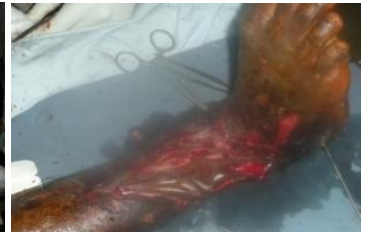

Photo $n^{\circ} 3$ 
Photo $\mathbf{n}^{\circ}$ 2, 3: management of an open leg fracture infected support to the bone consolidation andcovered the defect with a skin full thickness skin graft.

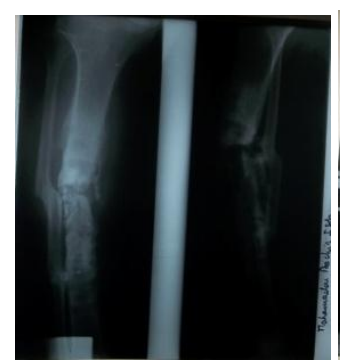

Photo $n^{\circ} 4$

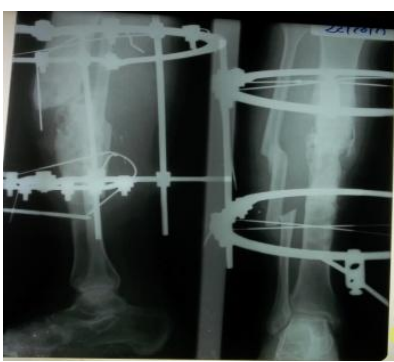

Photo ${ }^{\circ} 5$

Photo ${ }^{\circ} \mathbf{4}, \mathbf{5}$ : Infected pseudarthrosis of the leg treated by Ilizarov frame. 